\title{
Studies towards the synthesis of dictyolomides A and B, and
}

\section{6-methoxydictyolomide}

\author{
Patricia Domingos Duarte*, Arlene G. Corrêa \\ Chemistry Departament, Federal Universty of São Carlos, São Carlos, SP-Brazil \\ *Corresponding author. Tel.: +55 1633518215 ; e-mail: pathychem@gmail.com
}

Keywords: Dictyolomides, Leishmaniose, stereochemistry

\section{INTRODUCTION}

Leishmaniasis is a tropical disease caused by protozoa parasites of the genus Leishmania and remains a significant health issue in large part due to the lack of effective and affordable drugs and increasing resistance against existing drugs. ${ }^{1}$

4-Quinolones, for example dictyolomides, have been reported as potential antileishmanial agents. ${ }^{2}$ In this work we describe the studies towards the synthesis of dictyolomides $A$ and $B$, and 6methoxydictyolomide which will be evaluated against Leishmania sp and determine the stereochemistry of the center 3'.

\section{RESULTS AND DISCUSSION}

We proposed a convergent synthesis for dictiolomides as described in Scheme $1 .^{3}$

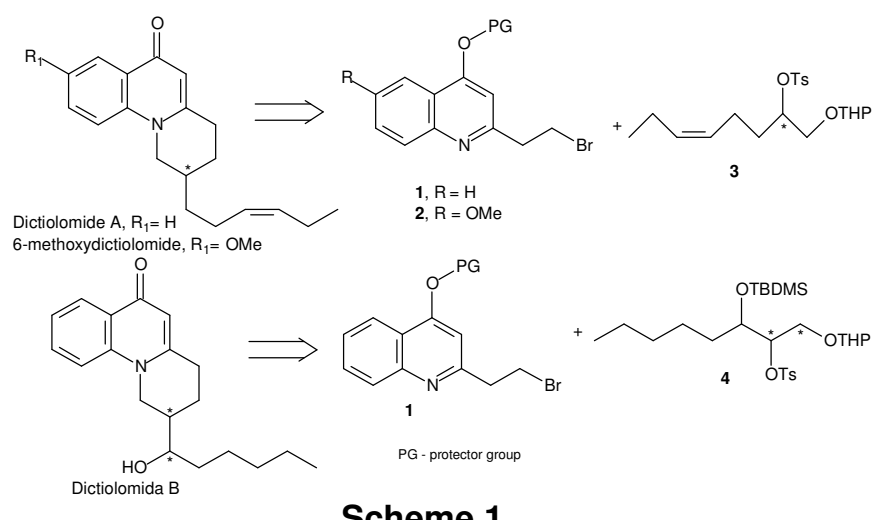

\section{Scheme 1}

The synthesis of bromides $\mathbf{1}$ and $\mathbf{2}$ began with the methodology reported by Kaslow et al. ${ }^{4}$, where 4quinolinone derivatives were prepared employing the condensation of aryl amines with ethyl acetonedicarboxylate, in refluxing, under acid catalyzes, following by cyclization at $250^{\circ} \mathrm{C}$ using phenyl ether as solvent. After, the reduction of the ester group was performed using borane, followed by bromination, and protection of the quinolinone ring with TBDMSCI (Scheme 2).

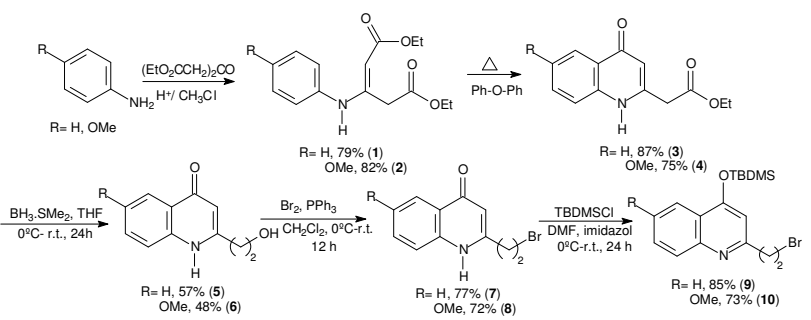

\section{Scheme 2. Preparation of bromides 1 and 2}

The synthesis of tosylates $\mathbf{3}$ and $\mathbf{4}$ are being studied, some tests were performed, but the coupling, via Grignard reaction ${ }^{5}$ has not yet provided tosylate 3 satisfactory (Scheme 3).
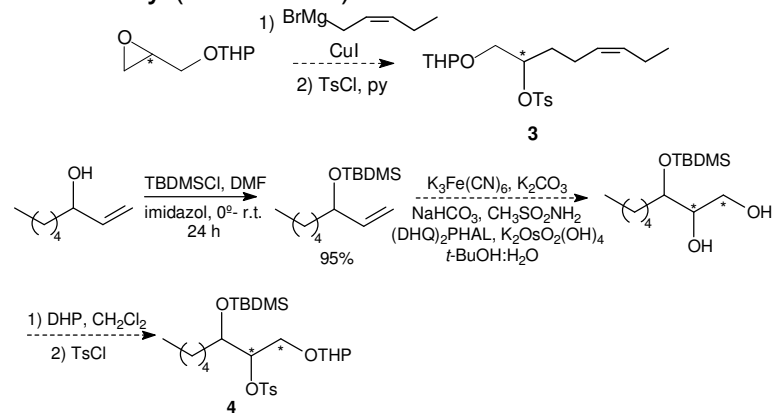

Scheme 3

\section{CONCLUSION}

In conclusion, bromides $\mathbf{1}$ and $\mathbf{2}$ were successfully synthesized. The studies for the synthesis of $\mathbf{3}$ will continue, and the synthesis of tosylate $\mathbf{4}$ will be completed, for subsequent coupling reaction and obtaining Dictiolomides.

\section{ACKNOWLEDGEMENTS}

CAPES, CNPq and FAPESP

\section{REFERENCES}

1Jain, M.; Khan, S.I.; Tekwani, B.L.; Jacob, M.R.; Singh, S.; Singh, P.P.; Jain, R. Bioorg. Med. Chem.2005,13, 4458.

${ }^{2}$ Ambrozin, A.R.P.; Leite, A.C.; Silva, M., et al. Pharmazie 2005, 60, 781.

${ }^{3}$ Baraldil, P. T., et al. 11 ${ }^{\text {th }}$ BMOS, Canela - RS, 2005, Abstracts p. 231.

${ }^{4}$ Kaslow, C.E.; Nix, S.J. J. Org. Chem. 1951, 16, 895

${ }^{5}$ Bates, R.W.; Song, P., Synthesis, 2009, 655. 